\title{
DINÂMICA SOROLÓGICA DE ANTICORPOS CONTRA Neospora caninum DURANTE A GESTAÇÃO DE VACAS NATURALMENTE INFECTADAS
}

\section{ANTIBODIES LEVELS AGAINST Neospora caninum DURING PREGNANCY IN NATURALLY INFECTED DAIRY COWS}

\author{
Ana Maria Antonello ${ }^{1 *}$ \\ Giovana Camillo ${ }^{1}$ \\ Augusto Weber ${ }^{2}$ \\ Patrícia Braunig ${ }^{2}$ \\ Luis Antonio Sangioni² \\ Fernanda Silveira Flores Vogel ${ }^{2}$ \\ ${ }^{1}$ Universidade Federal do Rio Grande do Sul, Porto Alegre, RS, Brasil. \\ 2 Universidade Federal de Santa Maria, Santa Maria, RS, Brasil. \\ *Autora para correspondência - ana_antonello@hotmail.com
}

\begin{abstract}
Resumo
Neosporose é uma das maiores causas de perdas reprodutivas em rebanhos bovinos. O estágio da gestação em que ocorre a infecção ou o recrudescimento das formas bradizoítas, que se reflete no nível de anticorpos, é um dos fatores que define o futuro da gestação. Portanto, este trabalho visa a traçar um esboço do perfil sorológico de fêmeas naturalmente infectadas durante a gestação. Para isso, amostras séricas de 25 vacas da raça holandesa foram coletadas desde o dia da inseminação artificial até a véspera do parto, em intervalos mensais. Essas amostras foram testadas por imunofluorescência indireta em busca de IgG. Dos 25 animais, somente 13 foram utilizados na análise, por serem soropositivos desde o início ou por se soroconverteram durante a gestação. Observou-se um aumento gradual dos níveis de anticorpos ao longo da gestação, mais evidente na metade final do período. Observou-se também diferença significativa nos títulos de anticorpos entre os períodos iniciais e finais da gestação, sugerindo a reativação de formas bradizoítas. Tais resultados reforçam a ideia da flutuação nos níveis de anticorpos ao longo da gestação, influenciado pela reativação de $N$. caninum. O conhecimento dessa dinâmica é importante para a patogenia e epidemiologia da infecção bem como para o diagnóstico.
\end{abstract}

Palavras-chave: bovinos; gestação; imunofluorescência indireta; Neosporose; sorologia.

\begin{abstract}
Neosporosis is one of the major causes of reproductive failure in bovine around the world. The period of gestation, in which the infection or the recrudescence of bradzoites forms occurs and reflects in the antibodies levels, is one of the factors that define pregnancy future. Therefore, this study aimed to determine the serological profile during pregnancy of naturally infected females. To do that, serological samples of 25 Holstain Friesian cows were collected from artificial insemination day until parturition, in monthly intervals. These samples were tested by indirect immunofluorescence for IgG anti-Neospora caninum. Of the 25 animals, only 13 were used in the analysis, because they were seropositive since the beginning or seroconverted during pregnancy. The results showed a gradual increase in antibody levels along pregnancy, more visible at the end of the period. We observed a significant difference in antibodies title between initial and final periods of pregnancy,
\end{abstract}


which suggests the reactivation of bradzoite forms present in tissues during pregnancy. These results reinforce the knowledge of antibodies fluctuation along pregnancy, affected by $N$. caninum reinfection or reactivation. This serological knowledge is important to Neosporosis pathogeny, epidemiology and diagnostic.

Keywords: bovine; indirect immunofluorescence; neosporosis; pregnancy; serology.

Recebido em: 01 fev. 2014

Aceito em: 25 fev. 2015

\section{Introdução}

Neosporose bovina é considerada, atualmente, uma das maiores causas de perdas reprodutivas em rebanhos bovinos em todo o mundo ${ }^{(1)}$. A enfermidade é causada pelo parasita Neospora caninum, um protozoário intracelular obrigatório, pertencente ao filo apicomplexa, que apresenta grande importância na pecuária, sendo a enfermidade considerada de caráter emergente, principalmente devido aos problemas reprodutivos envolvidos ${ }^{(2)}$. Este agente tem como hospedeiro definitivo cães domésticos, coiotes, dingos e lobos ${ }^{(3-6)}$. Estes animais excretam oocistos do protozoário nas fezes que, após esporulação no ambiente, são ingeridos pelos hospedeiros intermediários, via água ou alimento contaminado.

Bovinos, assim como uma ampla variedade de espécies de mamíferos, são considerados hospedeiros intermediários desta protozoose ${ }^{(7)}$. Contudo, é nessa espécie que a infecção pelo $N$. caninum apresenta as maiores consequências, principalmente relacionadas à reprodução. A principal forma de manutenção e transmissão deste protozoário nos rebanhos é por meio da infecção vertical e, uma vez que a fêmea é cronicamente infectada, a maioria das infecções congênitas resulta no nascimento de bezerros infectados e portadores de $N$. caninum $^{(8)}$. A possibilidade de fêmeas infectadas apresentarem distúrbios reprodutivos, como retorno ao cio e abortos, é de três a sete vezes maior que a de fêmeas não infectadas. Além disto, a infecção por este protozoário pode resultar em natimortos, mortalidade neonatal, morte fetal prematura e consequente retorno ao cio, aumento no intervalo entre partos, descarte precoce de animais e ainda está relacionada à redução na produção de leite ${ }^{(9)}$.

As consequências da infecção/recrudescência do N. caninum para o feto são mais severas no início da gestação, já o risco de transmissão transplacentária aumenta com o avançar da idade gestacional ${ }^{(10-12)}$. A resposta por anticorpos contra $N$. caninum é uma ótima ferramenta para diagnóstico e estudos epidemiológicos. O título de anticorpos é um indicador indireto da exposição do sistema imune a antígenos do protozoário. Um aumento no título de anticorpos pode indicar reativação e multiplicação do $N$. caninum. Neste sentido, o aumento no título de anticorpos em fêmeas portadoras, durante a gestação, pode ser reflexo da reativação do protozoário. Com isso, este artigo tem por objetivo traçar o perfil sorológico de fêmeas bovinas naturalmente infectadas pelo $N$. caninum durante a gestação.

\section{Material e Métodos}

Foram coletadas amostras de sangue de bovinos da raça Holandesa com idade entre 3 a 7 anos. Apesquisa foi iniciada em março de 2009. As amostras de soro de fêmeas foram selecionadas aleatoriamente de uma propriedade com análise prévia positiva para $N$. caninum, pela técnica de imunofluorescência indireta (IFI). No decorrer do estudo, 25 animais foram acompanhados; destes, oito permaneceram soronegativos durante todo o período de observação (8/25), quatro (4/25) apresentaram anticorpos em dois episódios e com títulos considerados baixos (100 e 200), sendo considerados negativos, portanto um total de 12 animais $(12 / 25 ; 48 \%)$ foi desconsiderado na análise. O perfil sorológico dos animais durante a gestação foi traçado utilizando-se apenas os 13 animais $(13 / 25 ; 52 \%)$ que foram reagentes por todo o período gestacional $(10 / 13)$ ou que soro-converteram durante este período (3/13).

As coletas foram realizadas mensalmente entre 2009 e 2010, imediatamente a partir do dia da Inseminação Artificial (IA) até a véspera do parto. O soro foi recuperado das amostras de sangue por 
meio de centrifugação (1500 rpm por 10 minutos) e armazenado a $-20{ }^{\circ} \mathrm{C}$ até o momento da análise. Para detecção de anticorpos contra $N$. caninum, as amostras de soro foram submetidas à técnica de imunofluorescência indireta (IFI) para pesquisa de imunoglobulinas G (IgG).

Taquizoítos de Neospora caninum da cepa NC-1, cultivados em células VERO, foram utilizados como antígenos para a realização da reação de IFI. O preparo das lâminas de IFI foi realizado a partir da monocamada celular infectada, centrifugada a 1500 x g por 10 minutos, por três vezes; o pellet final foi ressuspendido em PBS, distribuído em lâminas multispot, que foram fixadas com metanol $100 \%$ e armazenadas a $-20{ }^{\circ} \mathrm{C}$ até o momento do uso.

As amostras de soro foram diluídas inicialmente a 1:100 em PBS $(\mathrm{pH} 7,2)$ para a triagem dos animais e, a partir disso, para determinar o maior título da reação. Anticorpo anti-IgG bovina conjugado a fluoresceína (Sigma Aldrich ${ }^{\circledR}$ ) foi usado como anticorpo secundário na reação. Amostras de soro sabidamente positiva e negativa quanto à presença de anticorpos contra $N$. caninum foram utilizadas como controle positivo e negativo, respectivamente. Foram consideradas positivas as amostras em que houve fluorescência em toda a superfície dos taquizoítos de $N$. caninum e negativas as amostras em que a fluorescência era apical ou ausente ${ }^{(13)}$.

Para aproximação da normalidade, os dados dos títulos foram corrigidos por $\log _{10}(\mathrm{Y}+1,5)$, porém, para melhor visualização, os dados foram expressos de forma não transformada. A diferença entre os níveis de anticorpos de cada coleta e o período gestacional foi calculado pelo teste ANOVA, seguido pelo teste Tukey para comparação das médias com índice de confiabilidade de 95\% (GraphPadPrism $\left.5^{\circledR}\right)^{(14)}$.

\section{Resultados e Discussão}

Os anticorpos anti- $N$. caninum dos diferentes animais detectados nos diferentes períodos de coleta estão apresentados na Tabela 1. Do total de animais, 24 das fêmeas gestantes (24/25) pariram bezerros saudáveis. Uma vaca (1/25) pariu de forma prematura um bezerro viável. A média de IA por gestação bem sucedida foi 1,68 . Não houve diferença estatística quanto à média de IA entre as vacas soronegativas e soropositivas para o protozoário (Tabela 1).

Na primeira coleta, no dia da IA (dia 0), a média dos títulos corrigida pelo logaritmo (expressos em número médio geométrico) das fêmeas reagentes foi de 1,86, já na última coleta (dia 270), na véspera do parto, essa media foi de 2,65 (Tabela 1). Considerando-se estas médias, os títulos de anticorpos das 13 fêmeas monitoradas durante o período de gestação foram superiores aos níveis encontrados no dia da inseminação artificial IA. Estes dados sorológicos podem indicar, de forma indireta, que nestes animais houve uma reativação do protozoário durante o período de gestação, que promoveu a elevação nos níveis de $\mathrm{IgG}$ detectáveis.

Não foram observados sinais de aborto nos animais acompanhados durante o experimento. Entretanto, é interessante ressaltar que uma das fêmeas soropositivas teve sua gestação reduzida e pariu um terneiro de forma prematura, aos 240 dias de gestação aproximadamente. Inicialmente, este animal não apresentou variação nos níveis de anticorpos até momentos que antecederam o parto, (Tabela 1, Animal 21), quando o título de anticorpos teve uma elevação de 100 para 800. Esta dinâmica de imunoglobulinas sugere que neste período pode ter havido a recrudescência de bradizoítos dos tecidos do animal, que se refletiu no estímulo do sistema imunológico, elevando o nível de IgG. Este fato pode ter contribuído para anteceder o parto neste animal ${ }^{(15)}$.

A relação parasita-hospedeiro no animal infectado $\operatorname{com} N$. caninum durante a gestação é uma interação dinâmica entre sistema imunológico da mãe e o fetal em desenvolvimento e parasita ${ }^{(16)}$. Dentre os 13 animais considerados na análise, ficou evidente a variação nos níveis de anticorpos durante a gestação, apesar de não ter sido observada diferença significativa na variação entre coletas consecutivas; no entanto, observou-se um crescimento gradativo dos títulos, o que indica uma provável reativação do protozoário.

Ao se dividir a gestação em três períodos, a média do nível de IgG foi de 2,12 no primeiro terço (dia 0 a 90), 2,70 no segundo terço (dia 120 a 180) e novamente 2,70 no terço final (dia 210 a 270), comparando-se as médias dos títulos dos três terços gestacionais, nota-se que há diferença nos níveis de anticorpos do primeiro terço de gestação em relação aos demais $(\mathrm{P}<0,0001 ; \mathrm{IC}=95 \%)$, não 
ocorrendo, no entanto, diferença significativa entre os dois terços finais da gestação (Figura1B). Este dado corrobora outros estudos realizados com soro sanguíneo e leite, que demonstram que o período mais provável para reativação do protozoário ocorre entre o quarto e sexto mês de gestação ${ }^{(17,18)}$. Assim, os títulos no último terço gestacional são reflexo da possível reativação que ocorreu no segundo terço de gestação. Além disto, o aumento nos títulos de anticorpos é mais visível a partir do quinto mês de gestação (Figura 1A). A maioria dos abortos causados pelo N. caninum são diagnosticados entre três e oito meses de gestação ${ }^{(19)}$, período que corresponde ao aumento do título de $\operatorname{IgG}$ nas fêmeas gestantes, indicando maior atividade do parasita. Dessa forma, a mensuração do nível de anticorpos no início da gestação não é eficaz para predizer se o resultado da gestação será um aborto ou o nascimento de um animal infectado ou mesmo saudável, assim como sugere Guy et al. ${ }^{(20)}$.

Tabela 1: Acompanhamento sorológico ao longo da gestação de vacas naturalmente infectadas por N. caninum

\begin{tabular}{|c|c|c|c|c|c|c|c|c|c|c|c|}
\hline Animal & $\begin{array}{c}\mathbf{n}^{0} \\
\mathbf{I A}^{\dagger}\end{array}$ & $\begin{array}{c}\text { Dia } \\
0\end{array}$ & $\begin{array}{c}\text { Dia } \\
\mathbf{3 0}\end{array}$ & $\begin{array}{c}\text { Dia } \\
60\end{array}$ & $\begin{array}{c}\text { Dia } \\
90\end{array}$ & $\begin{array}{l}\text { Dia } \\
120\end{array}$ & $\begin{array}{l}\text { Dia } \\
150\end{array}$ & $\begin{array}{l}\text { Dia } \\
180\end{array}$ & $\begin{array}{l}\text { Dia } \\
210\end{array}$ & $\begin{array}{l}\text { Dia } \\
240\end{array}$ & $\begin{array}{l}\text { Dia } \\
270\end{array}$ \\
\hline $2^{*}$ & 1 & 0 & 0 & 200 & 200 & 400 & 200 & 200 & NA & 100 & 200 \\
\hline $3^{*}$ & 1 & 400 & 800 & NA & 1600 & NA & 6400 & 1600 & 3200 & 800 & 1600 \\
\hline $4^{*}$ & 1 & 100 & 100 & 200 & 200 & 200 & 100 & NA & 400 & 200 & 200 \\
\hline $6^{*}$ & 2 & 0 & 0 & 0 & 0 & 100 & 400 & 800 & 800 & 400 & 400 \\
\hline $9 *$ & 3 & 200 & 200 & 200 & 200 & 200 & 200 & 400 & 800 & 400 & 400 \\
\hline $13^{*}$ & 2 & 800 & 1600 & 800 & 800 & 1600 & 1600 & 3200 & 3200 & 1600 & 1600 \\
\hline $14^{*}$ & 2 & 100 & 100 & 200 & 200 & $\mathrm{NA}$ & 400 & 200 & 200 & 200 & 200 \\
\hline $15^{*}$ & 2 & 200 & 100 & 200 & 200 & 400 & 200 & 400 & 400 & 400 & 200 \\
\hline $16^{*}$ & 1 & 0 & 100 & 100 & 200 & 400 & 400 & 800 & 1600 & 400 & 800 \\
\hline $19 *$ & 2 & 100 & 200 & 400 & 200 & 800 & 400 & 400 & 400 & 200 & 200 \\
\hline $20^{*}$ & 1 & 100 & 200 & 200 & 200 & 200 & 400 & 400 & 400 & 400 & 400 \\
\hline $21^{*}$ & 1 & 100 & 100 & 200 & 200 & 400 & 200 & 200 & 100 & 800 & NA \\
\hline $23^{*}$ & 1 & 3200 & NA & 6400 & 6400 & 3200 & 6400 & 1600 & 1600 & 800 & 1600 \\
\hline 1 & 2 & 0 & 0 & 0 & 0 & 0 & 0 & 0 & 0 & 0 & 0 \\
\hline 5 & 1 & 0 & 0 & 0 & 0 & 0 & 0 & 0 & 0 & 0 & 0 \\
\hline 7 & 3 & 0 & 0 & 0 & 0 & 0 & NA & NA & 0 & 0 & 0 \\
\hline 8 & 1 & NA & 0 & 0 & 0 & 0 & 0 & 0 & 0 & 0 & 0 \\
\hline 10 & 3 & 0 & 0 & 0 & 0 & 0 & 0 & 0 & 0 & 200 & 0 \\
\hline 11 & 1 & 0 & 0 & 0 & 200 & 0 & 0 & 0 & 0 & 0 & 0 \\
\hline 12 & 1 & 0 & 0 & 0 & 0 & 0 & 100 & NA & 0 & 0 & 0 \\
\hline 17 & 3 & 0 & 0 & 0 & 0 & 0 & 0 & 0 & 0 & 0 & 0 \\
\hline 18 & 3 & 0 & 100 & 0 & 0 & 0 & 0 & 0 & 0 & 0 & 100 \\
\hline 24 & 1 & 0 & NA & 0 & 0 & 0 & 0 & 0 & 0 & 0 & 0 \\
\hline 25 & 1 & 0 & NA & 0 & 0 & 0 & 0 & 0 & 0 & 0 & 0 \\
\hline 26 & 2 & 0 & NA & 0 & 0 & 0 & 0 & 0 & 0 & 0 & 0 \\
\hline \multirow{2}{*}{ Média** } & \multirow{2}{*}{1,68} & 1,86 & 1,95 & 2,30 & 2,37 & & & & & & \\
\hline & & 0 & 0 & 2 & 1 & 2,632 & 2,697 & 2,754 & 2,829 & 2,604 & 2,654 \\
\hline
\end{tabular}

*Fêmeas gestantes que foram reagentes durante todo período ou que soro-converteram durante a gestação, consideradas nas análises estatisticas. ** Para o cálculo das médias de cada coleta foram considerados somente os 13 animais que foram positivos ou soro-converteram durante a gestação, permanecendo reagentes por pelo menos quatro coletas consecutivas. Os valores das médias dos títulos estão representados pelos valores transformados pela equação logarítmica $\log (\mathrm{X}+1,5)$.

†Número de inseminações artificiais por gestação bem sucedida. NA: não analisado. 
$\mathbf{A}$

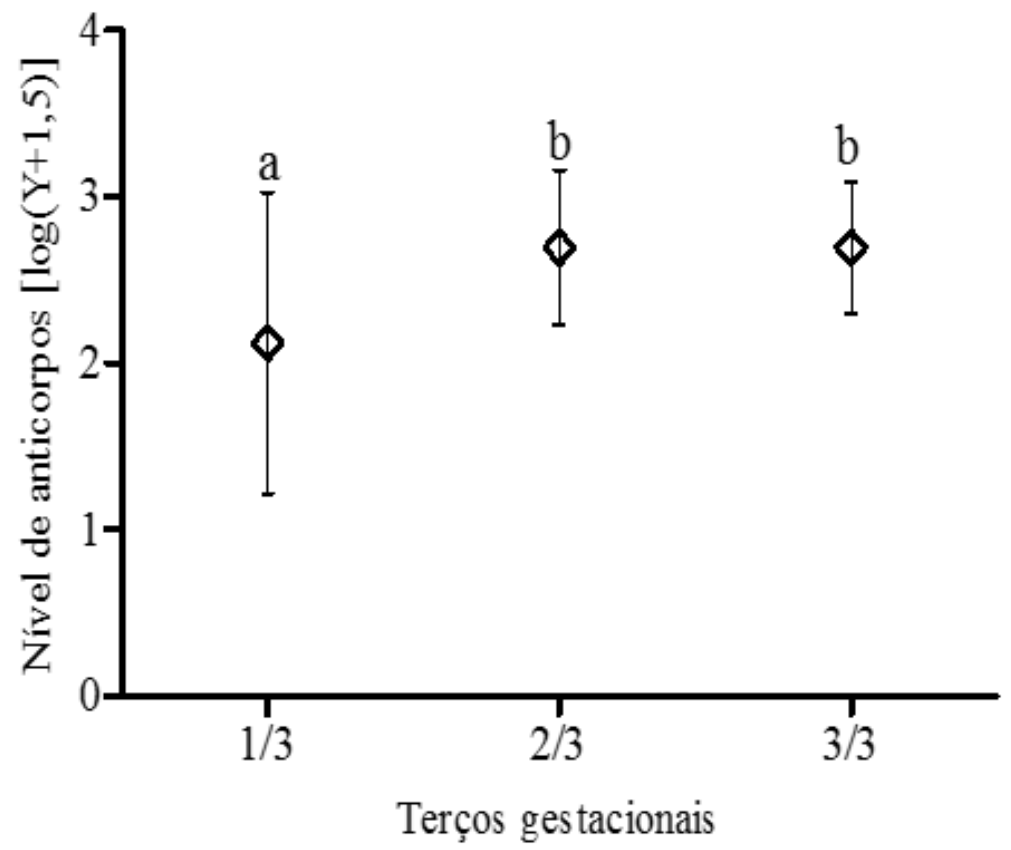

B

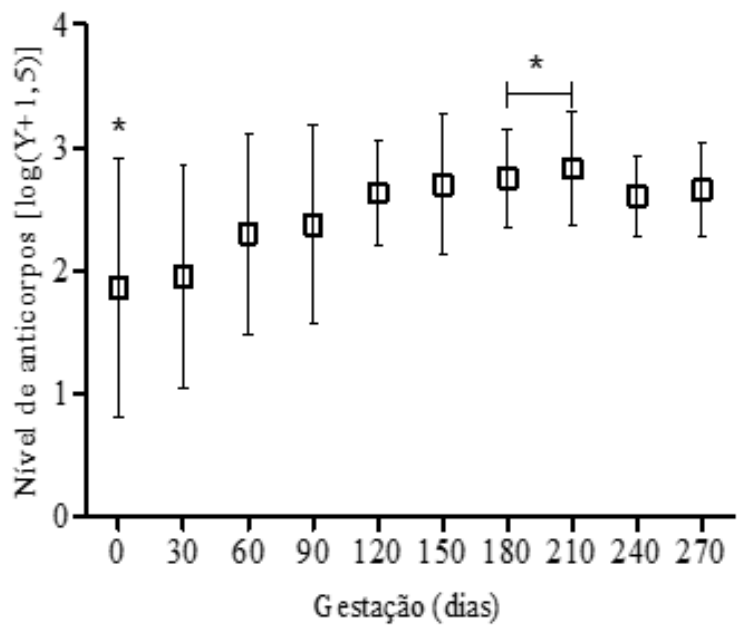

Figura 1: Dinâmica dos níveis de IgG contra $N$. caninum durante a gestação de vacas naturalmente infectadas. A - média do nível de anticorpos nos três terços da gestação, letras diferentes indicam diferença significativa entre os períodos: primeiro terço $(2,12)$ e os demais $(2,70) \quad(\mathrm{P}<0,0001$; IC $=95 \%$ ); B - média do nível de anticorpos durante a gestação, os asteriscos indicam diferença significativa somente entre o dia 0 e os dias 180 e 210 ( $\mathrm{P}<0,002 ; \mathrm{IC}=95 \%)$. Foram considerados 13 animais que soro-converteram ou mantiveram os títulos por toda gestação; os valores foram normalizados por $\log (\mathrm{Y}+1,5)$ e as médias de cada período foram comparadas por ANOVA seguido do teste Tukey.

Apesar de a resposta imune celular provavelmente ser a mais decisiva para evitar ou determinar a recrudescência do N. caninum, a resposta humoral é uma boa ferramenta para indicar a atividade do parasita no hospedeiro, sendo o título de anticorpos um indicador indireto da exposição antigênica para o sistema imunológico ${ }^{(9)}$. Durante a gestação, pode ocorrer a reativação de bradizoítos devido à modulação da resposta celular para humoral que ocorre na fêmea nesse período, uma vez que a restrição da proliferação de taquizoítos é feita pela imunidade celular. Porem, nestes animais a resposta celular está diminuída pela ação de citocinas, ao passo que a atividade humoral não é capaz de debelar a infecção de forma eficiente ${ }^{(16)}$. Este fenômeno pode tornar mais permissiva a conversão de bradizoítos em taquizoítos de $N$. caninum, que ocasionarão a infecção da placenta e possivelmente 
do feto ${ }^{(21)}$.

Estudos demonstram que o aumento no título de anticorpos que ocorre no decorrer da gestação, mais notadamente do segundo terço para o final, deve-se também ao aumento do nível de progesterona produzido pela placenta com a evolução da gestação, que atua diretamente na modulação da resposta imune $^{(22,23)}$. A progesterona desvia a resposta imune celular para humoral, levando a um downregulation na resposta por IFN-y, o que favorece a recrudescência do $N$. caninum $^{(16,24)}$. Garcia-Ispierto et al. ${ }^{(23)}$ ainda relatam que animais com títulos de anticorpos mais elevados também apresentam níveis de progesterona mais alto que animais soronegativos ou com baixos títulos. Além disso, estudos sugerem que a progesterona induz a produção de um fator bloqueador (progesterone-induced blocking factor - PIBF), que afeta a eficiência das IgG contra $N$. caninum, deixando os animais mais expostos aos efeitos lesivos da infecção pelo protozoário durante a gestação ${ }^{(25)}$.

Somando-se a isso, a variação nos níveis de anticorpos observados nas fêmeas durante a gestação pode dificultar o diagnóstico dependendo do ponto de corte e da técnica utilizada. Muitos laboratórios de diagnóstico utilizam a diluição do soro em 1:200, neste caso, aumentaria o número de resultados falso negativos. Assim, considerando esta metodologia de análise, sugere-se que para se determinar se um animal é soronegativo para o $N$. caninum, deveriam ser realizadas pelo menos duas amostragens em momentos distintos da gestação para reduzir o risco de falso negativo. Por outro lado, a utilização da diluição do soro em 1:200 diminui a probabilidade de ocorrência de falso positivo em virtude de reduzir a ocorrência de reatividade sorológica cruzada entre protozoários do filo Apicomplexa.

\section{Conclusão}

Os resultados obtidos no presente estudo reforçam a ocorrência de flutuação nos níveis de anticorpos anti- $N$. caninum durante a gestação. O conhecimento dessa dinâmica é importante no que diz respeito tanto à patogenia, mas principalmente quanto ao diagnóstico, relacionado à diluição do soro a ser testado e à eleição de testes pareados no diagnóstico sorológico da neosporose bovina.

\section{Referências}

1.Dubey JP, Lindsay DS, Adams DS, Gay JM, Baszler TV, Blagburn BL, et al. Serologic responses of cattle and other animals infected with Neospora caninum. American journal of veterinary research. 1996;57(3):32936. Disponível em: http://www.ncbi.nlm.nih.gov/pubmed/8669764

2.Anderson ML, Andrianarivo AG, Conrad PA. Neosporosis in cattle. Animal reproduction science. 2000;6061:417-31. Disponível em: http://www.ncbi.nlm.nih.gov/pubmed/10844212

3.McAllister MM, Dubey JP, Lindsay DS, Jolley WR, Wills RA, McGuire AM. Dogs are definitive hosts of Neospora caninum. International journal for parasitology. 1998;28(9):1473-8. Disponível em: http://www. ncbi.nlm.nih.gov/pubmed/9770635

4.Gondim LF, McAllister MM, Pitt WC, Zemlicka DE. Coyotes (Canis latrans) are definitive hosts of Neospora caninum. International journal for parasitology. 2004;34(2):159-61. Disponível em: http://www.ncbi.nlm.nih. gov/pubmed/15037103

5.King JS, Slapeta J, Jenkins DJ, Al-Qassab SE, Ellis JT, Windsor PA. Australian dingoes are definitive hosts of Neospora caninum. International journal for parasitology. 2010;40(8):945-50. Disponível em: http://www. ncbi.nlm.nih.gov/pubmed/20149793

6.Dubey JP, Jenkins MC, Rajendran C, Miska K, Ferreira LR, Martins J, et al. Gray wolf (Canis lupus) is a natural definitive host for Neospora caninum. Veterinary parasitology. 2011;181(2-4):382-7. Disponível em: http://www.ncbi.nlm.nih.gov/pubmed/21640485

7.Dubey JP. Neosporosis in cattle. The Veterinary clinics of North America Food animal practice. 2005;21(2):473-83. Disponível em: http://www.ncbi.nlm.nih.gov/pubmed/15955441

8.Trees AJ, Williams DJ. Endogenous and exogenous transplacental infection in Neospora caninum and Toxoplasma gondii. Trends in parasitology. 2005;21(12):558-61. Disponível em: http://www.ncbi.nlm.nih. gov/pubmed/16223599

9.Innes EA. The host-parasite relationship in pregnant cattle infected with Neospora caninum. Parasitology. 
2007;134(Pt 13):1903-10. Disponível em: http://www.ncbi.nlm.nih.gov/pubmed/17958926

10.Williams DJ, Guy CS, McGarry JW, Guy F, Tasker L, Smith RF, et al. Neospora caninum-associated abortion in cattle: the time of experimentally-induced parasitaemia during gestation determines foetal survival. Parasitology. 2000;121 ( Pt 4):347-58. Disponível em: http://www.ncbi.nlm.nih.gov/pubmed/11072897

11.Maley SW, Buxton D, Rae AG, Wright SE, Schock A, Bartley PM, et al. The pathogenesis of neosporosis in pregnant cattle: inoculation at mid-gestation. Journal of comparative pathology. 2003;129(2-3):186-95. Disponível em: http://www.ncbi.nlm.nih.gov/pubmed/12921725

12.Macaldowie C, Maley SW, Wright S, Bartley P, Esteban-Redondo I, Buxton D, et al. Placental pathology associated with fetal death in cattle inoculated with Neospora caninum by two different routes in early pregnancy. Journal of comparative pathology. 2004;131(2-3):142-56. Disponível em: http://www.ncbi.nlm. nih.gov/pubmed/15276854

13.Pare J, Hietala SK, Thurmond MC. Interpretation of an indirect fluorescent antibody test for diagnosis of Neospora sp. infection in cattle. Journal of veterinary diagnostic investigation : official publication of the American Association of Veterinary Laboratory Diagnosticians, Inc. 1995;7(2):273-5. Disponível em: http:// www.ncbi.nlm.nih.gov/pubmed/7619917

14.Motulsky HJ. Prism 5 Statistics Guide. 5.0 ed. San Diego CA: GraphPad Software Inc.; 2007.

15.Davison HC, Guy F, Trees AJ, Ryce C, Ellis JT, Otter A, et al. In vitro isolation of Neospora caninum from a stillborn calf in the UK. Research in veterinary science. 1999;67(1):103-5. Disponível em: http://www.ncbi. nlm.nih.gov/pubmed/10425249

16.Innes EA, Wright S, Bartley P, Maley S, Macaldowie C, Esteban-Redondo I, et al. The host-parasite relationship in bovine neosporosis. Veterinary immunology and immunopathology. 2005;108(1-2):29-36. Disponível em: http://www.ncbi.nlm.nih.gov/pubmed/16098610

17.Stenlund S, Kindahl H, Magnusson U, Uggla A, Bjorkman C. Serum antibody profile and reproductive performance during two consecutive pregnancies of cows naturally infected with Neospora caninum. Veterinary parasitology. 1999;85(4):227-34. Disponível em: http://www.ncbi.nlm.nih.gov/pubmed/10488725

18.Almeria S, Nogareda C, Santolaria P, Garcia-Ispierto I, Yaniz JL, Lopez-Gatius F. Specific anti-Neospora caninum IgG1 and IgG2 antibody responses during gestation in naturally infected cattle and their relationship with gamma interferon production. Veterinary immunology and immunopathology. 2009;130(1-2):35-42. Disponível em: http://www.ncbi.nlm.nih.gov/pubmed/19201036

19.Dubey JP, Buxton D, Wouda W. Pathogenesis of bovine neosporosis. Journal of comparative pathology. 2006;134(4):267-89. Disponível em: http://www.ncbi.nlm.nih.gov/pubmed/16712863

20.Guy CS, Williams DJL, Kelly DF, McGarry JW, Guy F, Bjorkman C, et al. Neospora caninum in persistently infected, pregnant cows: spontaneous transplacental infection is associated with an acute increase in maternal antibody. The Veterinary record. 2001;149(15):443-9. Disponível em: http://www.ncbi.nlm.nih. gov/pubmed/11688746

21.Nishikawa Y, Inoue N, Xuan X, Nagasawa H, Igarashi I, Fujisaki K, et al. Protective efficacy of vaccination by recombinant vaccinia virus against Neospora caninum infection. Vaccine. 2001;19(11-12):1381-90. Disponível em: http://www.ncbi.nlm.nih.gov/pubmed/11163660

22.Senger PL. Placentation, the endocrinology of gestation and parturition. In: Senger PL, editor. Patways to pregnancy and parturition. 2 ed. Pulman, WA: Current Conception Inc; 2005. p. 304-25.

23.Garcia-Ispierto I, Nogareda C, Yaniz JL, Almeria S, Martinez-Bello D, de Sousa NM, et al. Neospora caninum and coxiella burnetii seropositivity are related to endocrine pattern changes during gestation in lactating dairy cows. Theriogenology. 2010;74(2):212-20. Disponível em: http://www.ncbi.nlm.nih.gov/ pubmed/20416940

24.Bech-Sabat G, Lopez-Gatius F, Santolaria P, Garcia-Ispierto I, Pabon M, Nogareda C, et al. Progesterone supplementation during mid-gestation increases the risk of abortion in Neospora-infected dairy cows with high antibody titres. Veterinary parasitology. 2007;145(1-2):164-7. Disponível em: http://www.ncbi.nlm.nih.gov/ pubmed/17182187

25.Druckmann R, Druckmann M-A. Progesterone and the immunology of pregnancy. The Journal of Steroid Biochemistry and Molecular Biology. 2005;97(5):389-96. Disponível em: http://www.sciencedirect.com/ science/article/pii/S0960076005003602 